\title{
UTILIZAÇÃO DE GÁS OZÔNIO NA DESINFECÇÃO DE RESÍDUOS DE SERVIÇOS DE
}

\author{
SAÚDE
}

\author{
Thais Nogueira Gonzaga ${ }^{1}$ \\ Dora Inés Kozusny-Andreani² \\ Recebido em: 26 fev. 2018 \\ Aceito em: 28 nov. 2018
}

\begin{abstract}
RESUMO: Nesta pesquisa objetivou-se avaliar a viabilidade técnica da aplicação de ozônio como bactericida e fungicida em amostras de resíduos de serviços de saúde potencialmente infectantes. Foram determinados os micro-organismos presentes nos resíduos gerados em um hospital particular. Para realização das análises microbiológicas e o tratamento com ozônio o material foi particulado e homogeneizado. As análises microbiológicas foram realizadas antes e após a ozonização. Para os testes de desinfecção foram retirados $10,0 \mathrm{~g}$ de amostra que foi submetida à ozonização por $5,10,15,20$ e 25 minutos com doses de 140,0; 280,0; 420,0; 560,0 e 700,0 $\mathrm{mg} \mathrm{L}^{-1}$ de ozônio, respectivamente. Verificou-se presença de mesófilos totais, coliformes totais e termotolerantes, Escherichia coli, Pseudomonas aeruginosa, Proteus spp., Staphylococcus aureus, Staphylococcus spp, Candida albicans e Rhizopus spp. O ozônio foi eficiente para eliminação de todos os micro-organismos em 20 minutos; nos primeiros cinco minutos de exposição ao gás verificou-se redução superior a $98 \%$.
\end{abstract}

Palavras-chave: Bactérias patogênicas. Fungos. Ozonização.

\section{USING OZONE GAS FOR DISINFECTION OF SOLID WASTE FROM HEALTH CARE}

\section{SERVICES}

ABSTRACT: The aim of this research was to evaluate the technical viability of the application of ozone as bactericide and fungicide in samples of potentially infectious health services residues. The microorganisms present in the waste generated in a private hospital were determined. The material was particulated and homogenized to perform the microbiological analysis and to undergo ozone treatment. Microbiological analysis was performed before and after ozonization. For the disinfection tests, $10.0 \mathrm{~g}$ of sample were removed and submitted to ozonization for $5,10,15,20$ and 25 minutes with 140,$0 ; 280,0 ; 420,0 ; 560,0$ and $700,0 \mathrm{mg}$ doses of $\mathrm{L}^{-1}$ of ozone, respectively. It was verified the presence of total mesophiles, total and thermotolerant coliforms, Escherichia coli, Pseudomonas aeruginosa, Proteus spp., Staphylococcus aureus, Staphylococcus spp, Candida albicans and Rhizopus spp. Ozone was efficient while eliminating all microorganisms in 20 minutes; in the first five minutes of gas exposure, the reduction was greater than $98 \%$.

Keywords: Pathogenic bacteria. Fungi. Ozonization.

\footnotetext{
1 Universidade Federal de Uberlândia.

2 Universidade Brasil - Campus Fernandópolis.
} 


\section{INTRODUÇÃO}

Os resíduos sólidos da saúde (RSS) incluem os materiais descartados e não tratados, provenientes de atividades de cuidados de saúde em seres humanos ou animais, que têm o potencial de transmitir agentes infecciosos. Estes incluem materiais ou equipamentos de diagnóstico, utilizados na avaliação do estado do paciente, no tratamento e na prevenção de doenças e avaliação do estado de saúde, que estiveram em contato com sangue e seus derivados, tecidos, fluidos de tecido ou excrementos ou resíduos de enfermarias. (COCCIA et al., 2010).

Os RSS podem apresentar riscos para a saúde humana quando são manuseados de maneira inadequada. Os riscos diretos e específicos para a saúde dizem respeito, principalmente, aos trabalhadores neste domínio, que devem ser protegidos do contato com os resíduos. Para o público em geral, os principais riscos para saúde são indiretos e decorrem da criação de vetores de doenças, principalmente moscas e ratos, quando não são gerenciados de forma apropriada (SINGH, 2013). O risco para a saúde humana e ao ambiente é devido ao fato de que esses resíduos podem conter uma grande variedade de micro-organismos patogênicos que geralmente incluem bactérias, vírus e fungos e, partículas proteicas infecciosas (prion) (SAINI et al., 2004; BLENKHARN, 2005; ALAGÖZ e KOCASOY, 2008).

As bactérias patogênicas isoladas com maior frequência são dos gêneros Bacillus, Staphylococcus e Streptococcus, juntamente com números variados de outras bactérias patogênicas nosocomiais comuns, como Klebsiella, Salmonella, Proteus e Enterobacter (COKER et al., 2009). No entanto, diversos estudos evidenciaram que as espécies microbianas mais prevalentes nos RSS são Staphylococcus aureus, Escherichia coli, Pseudomonas aeruginosa, Bacillus cereus, Lactobacillus spp., Staphylococcus spp., Micrococcus spp., Propionibacterium acnes, Enterobacter spp., leveduras (Candida albicans) e bolores (ALAGÖZ, KOCASOY, 2008; NASCIMENTO et al., 2009; PARK et al., 2009; BASSEY et al., 2015; CHAYB, KOZUSNY-ANDREANI, 2015; MARTINS et al., 2015).

A presença de micro-organismos patogênicos constitue-se em uma fonte potencial de epidemias e de doenças decorrentes do gerenciamento inadequado e do despejo em aterros sanitários de resíduos sólidos. Os aterros municipais de resíduos sólidos são fontes de poluição microbiana do ar. Os micro-organismos são transportados do aterro sanitário para a atmosfera com o vento. Sua sobrevivência depende da resistência, das condições meteorológicas, da poluição do ar e da permanência na atmosfera (TRAVERSI et al., 2011). Segundo Kaźmierczuk, Bojanowicz-Bablok (2014), os aterros são fontes de emissão e dispersão de aerossóis bacterianos e fúngicos, mesmo quando existe gestão correta e manutenção adequada, influenciando na qualidade do ar em uma distância de 1000-1200 $\mathrm{m}$.

Os resíduos sólidos não tratados contêm frequentemente agentes microbianos que possuim potencial de causar doenças infecciosas. O nível deste potencial frequentemente não é avaliado, mas nenhum processo de tratamento atual pode eliminar total ou 
consistentemente tais riscos, no entanto, o que está claro é que os processos de tratamento alteram a distribuição e a concentração de patógenos durante o mesmo. Os órgãos geradores de RSS devem evitar a mistura de resíduos essencialmente isentos de agentes patogênicos com outros contaminados por agentes infecciosos para melhorar as taxas e as intensidades dos processos de tratamento (HAMER, 2003).

Diante dos riscos potenciais que o manejo inadequado dos resíduos de serviços de saúde representa a saúde humana e animal, assim como ao meio ambiente, existe um interesse crescente em identificar uma tecnologia confiável para o manuseio e descarte seguro destes resíduos, entretanto podem ser garantidos poucos métodos de tratamento que permitam eliminar todos os agentes infecciosos. Os processos de tratamento envolvem a destruição ou inativação irreversível de todos os patógenos presentes e a prevenção da recontaminação subsequente ou reinfecção com organismos patogênicos (ZHANG et al., 2007; ALAGÖZ, KOCASOY, 2008; OLIVEIRA et al., 2010; HOSSAIN et al., 2012; MARTINS et al., 2015; MARTINELLI et al., 2017).

A gestão e eliminação segura dos RSS é problemática devido à natureza infecciosa dos mesmos e aos elevados custos de tratamento. Em todo o mundo, a tecnologia mais comumente usada para tratar os resíduos sólidos é a incineração. A vantagem deste método de tratamento é a redução considerável do volume dos resíduos, tornando-os irreconhecíveis (GAUTAM et al., 2010). Por outro lado, a incineração libera uma grande variedade de poluentes, incluindo dioxinas, furanos e metais pesados (chumbo, mercúrio e cádmio), gases ácidos (cloreto de hidrogênio e dióxido de enxofre), monóxido de carbono e óxido de nitrogênio (HAMER, 2003;; ÖKTEN et al., 2015). Estas emissões podem ter graves efeitos sobre a segurança dos trabalhadores, a saúde pública e ao ambiente (MATTIELLO et al., 2013; ASHWORTH et al., 2014).

A tecnologia de autoclave, que consiste na esterilização por meio da aplicação de vapor saturado, sob pressão, tem sido amplamente utilizada em instalações de saúde para descontaminar os resíduos de laboratório altamente infecciosos, porque é visto como o processo mais confiável e facilmente controlável. Tipicamente, as autoclaves são usadas em hospitais para a esterilização de equipamentos médicos reutilizáveis e têm provado ser muito eficazes para esse fim. Posteriormente, os mesmos parâmetros do processo foram aplicados para esterilizar resíduos clínicos com a hipótese de que uma autoclave poderia ser eficaz para esterilizar os RSS (HAMER, 2003; OLIVEIRA et al., 2010; ÖKTEN et al., 2015). O processo danifica termicamente a estrutura celular bacteriana, incluindo a membrana externa e citoplasmática, tornando a célula não mais viável (TORTORA et al., 2012). A inativação dos mecanismos vitais das células bacterianas depende da estrutura celular bacteriana, da temperatura e da duração da submissão ao calor a que estão expostos (HOSSAIN et al., 2012).

Nos últimos anos a utilização do ozônio tem se intensificado por ser um desinfetante de amplo espectro com capacidade de inativar uma ampla gama de micro-organismos que podem ser resistentes a outros desinfetantes (SHARMA, HUDSON, 2008; ROSENBLUM et al., 2012; MARTINS et al., 2015; MARTINELLI et al., 2017). O modo de ação do ozônio 
contra micro-organismos não está completamente definido. Alguns estudos sobre bactérias sugerem que o ozônio altera proteínas e ligações insaturadas de ácidos graxos na membrana celular, levando à lise celular (THANOMSUB et al., 2002). O ozônio pode interromper a atividade enzimática celular reagindo com grupos tiol e modificar as bases purinas e pirimidinas em ácidos nucleicos (RUSSELL, 2003). O ozônio é igualmente eficaz na destruição de ambos os vírus envelopados e não envelopados, produzindo danos no envelope e na capside (MURRAY et al, 2008). O ozônio pode constituir um sistema antimicrobiano alternativo eficaz, uma vez que é capaz de penetrar em todas as irregularidades superficiais e é aplicável a um amplo espectro antimicrobiano (WANI et al., 2015). Face ao exposto, objetivou-se nesta pesquisa avaliar a viabilidade técnica da aplicação de ozônio como bactericida e fungicida em amostras de RSS potencialmente infectantes.

\section{MATERIAL E MÉTODOS}

\section{ORIGEM E COLETA DAS AMOSTRAS DE RESÍDUOS DE SERVIÇOS DE SAÚDE}

Os resíduos foram coletados em um hospital particular, em Uberlândia/MG. A amostragem foi realizada em três diferentes setores do hospital: Unidade de Terapia Intensiva de Adultos (UTI adulto), Unidade de Internação e Unidade de Isolamento.

A coleta de resíduos em três locais distintos teve o intuito da obtenção de amostras representativas dos diferentes micro-organismos que poderiam estar presentes nos resíduos, nos diferentes locais.

As coletas foram realizadas no período da manhã. Nas operações de coleta foram retirados $2,0 \mathrm{~kg}$ de $\mathrm{RSS}$, em cada um dos locais escolhidos. Foram realizadas duas amostragens, com intervalo de, aproximadamente, trinta dias, totalizando seis amostras de material para o estudo. Em todos os procedimentos de coleta foram utilizados equipamentos de proteção individual (EPIs). Cada amostra de resíduo infectante foi acondicionada em saco plástico na cor branca leitosa, de capacidade compatível com a quantidade coletada, que foi devidamente fechado e, conservada em caixa isotérmica com gelo, transportada ao Laboratório para realização das análises microbiológicas e subsequente desinfecção com gás ozônio. Os procedimentos laboratoriais foram realizados sempre dentro das $24 \mathrm{~h}$ posteriores à amostragem.

\section{MEIOS DE CULTURA E ANÁLISE MICROBIOLÓGICA}

Para o cultivo de micro-organismos foram utilizados os seguintes meios de cultura: caldo de Lauril Triptose (LTB, OXOID®), caldo Verde Brilhante Bile (BGBB, OXOID®), ágar 
Triptecaseina Soja (TSA, OXOID®), ágar Eosina Azul de Metileno (EMB, OXOID®), ágar Salmonella Shigella (SS, OXOID®), ágar Sangue (TSA, OXOID®), ágar Sabouraud (HIMEDIA), ágar Baird Parker (OXOID®), ágar Cetrimide (OXOID®) e ágar seletivo para Clostridium (OXOID®), preparados de acordo com as recomendações do fabricante.

Para análise microbiológica foi empregada a metodologia preconizada pela American Public Health Association (APHA, 2012). Inicialmente, as amostras foram particuladas e homogeneizadas com auxílio de tesoura e espátula esterilizadas, em seguida foram coletadas sub amostras de 10,0g (em quadruplicata), para submissão à diluição seriada em $90 \mathrm{~mL}$ de solução salina ( $\mathrm{NaCl}$ 0,5\%) esterilizada.

Para a contagem de coliformes totais, preparou-se diluições seriadas, de amostras do RSS, em solução salina ( $\mathrm{NaCL}, 0,85 \%)$ e, uma alíquota $1 \mathrm{~mL}$ foi transferida assepticamente para uma série de tubos de ensaio contendo tubo de Durham invertido e caldo de Lauril Triptose (LTB). Os tubos foram agitados suavemente e incubados durante 48 horas a $37^{\circ} \mathrm{C}$. A produção de gás e a fermentação de lactose foram observadas como reações positivas.

Os coliformes termotolerantes foram determinados empregando-se diluições seriadas e uma alíquota de $1,0 \mathrm{~mL}$ foi transferida para tubos contendo tubo de Durham invertido e caldo Verde Brilhante Bile (BGBB). Os tubos foram agitados suavemente e incubados durante $48 \mathrm{~h}$ a $44,5^{\circ} \mathrm{C}$. A produção de gás e a fermentação de lactose foram observadas como reacções positivas.

Para 0 isolamento de outras bactérias e fungos, $0,1 \mathrm{~mL}$ de cada diluição foram inoculados em Placas de Petri sobre os meios específicos estéreis. Os inóculos foram espalhados pelas superfícies dos meios, com auxílio de alça de Drigalski e incubadas, à temperatura de $37^{\circ} \mathrm{C}$, por intervalos de tempo de 24-48h. Após esse período realizou-se a contagem e a avaliação das características das colônias quanto à forma, tamanho e cor. A quantificação foi expressa em unidades formadoras de colônias por grama de RSS (UFC g$1)$.

As bactérias e os fungos foram caracterizados, respectivamente, pela coloração de Gram e pelo Azul de Algodão e identificados por métodos bioquímicos, de acordo com a metodologia descrita por Winn et. al. (2008).

Para a identificação das espécies bacterianas Gram-negativas foi utilizado o sistema API 20E (Analytical Profile Index, BioMérieux) e para a caracterização das espécies bacterianas Gram-positivas foram realizados os testes bioquímicos: catalase, coagulase, DNAse, oxidase e hemólise.

Todos os experimentos para as análises microbiológicas, tanto das amostras coletadas do resíduo antes do tratamento quanto para as amostras do resíduo tratado, foram realizados em quadruplicata. 


\section{TRATAMENTO DO RSS COM OZÔNIO}

Para a realização dos testes de desinfecção foram retirados $10,0 \mathrm{~g}$ de cada uma das amostras particuladas e submetidos à ozonização, em intervalos de tempo de 5,10 , 15, 20 e 25 minutos com dose de 1400, 280,0 420,0 560,0 e 700,0 $\mathrm{mg} \mathrm{L}^{-1}$ de ozônio, respectivamente.

O ozônio foi obtido por um equipamento gerador corona, Modelo Ozone \& Life ${ }^{\circledR}$ (Medical System), sendo a concentração do gás limitada pelo equipamento, calibrado em uma vazão de $\mathrm{O}_{3}$ de $28 \mathrm{mg} \mathrm{L}^{-1}$. O fluxo de entrada do gás oxigênio $\left(\mathrm{O}_{2}\right)$ utilizado foi de $1 \mathrm{~L}$ por minuto de $\mathrm{O}_{2}$ e a temperatura do ambiente controlada entre $18-20^{\circ} \mathrm{C}$ durante todo $\mathrm{o}$ experimento. $\mathrm{O}$ gás ozônio foi conduzido ao recipiente de ozonização por meio de um tubo de silicone.

Finalizado cada período de ozonização foi retirada uma alíquota de 1,0g do material tratado para a repetição das análises microbiológicas, em proporção, tanto para a massa das amostras quanto para a quantidade do diluente (1,0g:9,0 mL).

\section{A CÂMARA DE OZONIZAÇÃO}

Foi utilizado um sistema de fumigação de ozônio modificado, proposto por Wani et al. (2015). Esta câmara foi projetada para melhorar a aplicação de ozônio nas superfícies a serem desinfetadas, para reduzir o tempo necessário de exposição dos materiais ao ozonio e para aumentar as concentrações de ozônio desejadas no interior da mesma. A câmara usada na ozonização foi confeccionada em vidro, em formato retangular, com dimensões de 25,5 x 25,0 x 15,3 cm $\left(9,7 \mathrm{~cm}^{3}\right.$ ou 9,7 L).

A câmara foi fechada na parte superior com uma tampa móvel para inserção e retirada do material. Nas extremidades foram colocados orifícios que permitissem a entrada e saída do gás. A amostra de RSS foi colocada no interior da câmara e foi então exposta ao ozônio, uma vez que a concentração desejada foi atingida.

\section{VARIAÇÃO DAS CARGAS MICROBIANAS NAS AMOSTRAS}

Nas amostras de resíduo tratadas in vitro foram avaliados os percentuais de redução da contagem microbiana devido à ação do ozônio, em função dos intervalos de tempos de tratamento $n(5,10,15,20$ e 25 minutos), em que a contagem inicial é a contagem microbiana antes do tratamento, por meio da seguinte expressão:

$$
\% \text { de redução da carga microbiana }=\frac{\left(\text { contagem }_{n \text { min }}-\text { contagem }_{\text {inicial }}\right)}{\text { contagem }_{\text {inicial }}}
$$


Os dados obtidos foram analisados por meio da análise descritiva da contagem microbiana de diversos micro-organismos contidos nas amostras dos resíduos de acordo com o local de coleta e o tratamento antimicrobiano de ozonização e a aplicação do teste de análise de variância com teste de comparação múltipla de Games-Howell, quando $p<0,05$, para a comparação da contagem microbiana referentes às amostras dos locais de coleta e aos tratamentos por ozonização. Todos os testes estatísticos foram aplicados com nível de significância de 5\% (ZAR, 2009). O software utilizado para a realização da análise foi Minitab 17 (Minitab Inc.)

\section{RESULTADOS E DISCUSSÃO}

Inicialmente, o estudo realizado permitiu a identificação e a quantificação dos microorganismos potencialmente infectantes presentes nas amostras de RSS coletadas nos três locais escolhidos: UTI adulto, unidade de internação e unidade de isolamento. Verificou-se presença de bactérias mesófilos totais, coliformes totais, coliformes termotolerantes, Escherichia coli, Pseudomonas aeruginosa, Proteus spp., Staphylococcus aureus, Staphylococcus spp, de leveduras da espécie Candida albicans e de bolores identificados como Rhizopus spp (Tabela 1). Estes resultados são equivalentes aos obtidos por Park et al. (2009) que detectaram uma série de micro-organismos, incluindo Pseudomonas spp. e Staphylococcus spp., em vários tipos de resíduos clínicos. Alagoz, Kocasoy (2008) realizaram análises microbiológicas em RSS para determinar a quantidade de bactérias patogênicas por métodos de contagem de colônias e detectaram bactérias coliformes, Escherichia coli, Enterobacter, Pseudomonas spp., Staphylococcus aureus, Bacillus cereus, Salmonella spp., Legionella, leveduras e bolores.

Os resultados da Tabela 1 indicam a presença de diferenças significativas em todas as comparações quantitativas dos micro-organismos das amostras colhidas nos três locais, exceto para Candida albicans que, por sua vez, apresentou contagem semelhante nas amostras dos resíduos dos três locais avaliados $(p=0,101)$. A análise comparativa não foi possível de ser realizada no caso da contagem do micro-organismo da espécie Proteus spp., pois não houve contagem microbiana para tal nas amostras do local UTI adulto, impossibilitando a comparação com as dos demais locais avaliados.

A contagem de mesófilos totais e coliformes totais apresentou diferenças significativas quando as amostras dos locais foram comparadas, sendo que as da unidade de isolamento foram as que apresentaram maior contagem para os micro-organismos mencionados e as da UTI adulto menor contagem microbiana. Para coliformes termotolerantes, E. coli e Staphylococcus spp. as contagens de micro-organismos das amostras das unidades de isolamento e de internação não diferiram entre si, mas tais valores médios diferiram de forma significativa das contagens observadas nas amostras da UTI adulto, que apresentaram menores quantidades de micro-organismos. Em pesquisa 
realizada por Chayb, Kozusny-Andreani (2015) nas análises microbiológicas dos resíduos sólidos infectantes obtidos de um hospital escola de Uberlândia-MG, foram encontradas bactérias patogênicas e oportunistas das espécies Escherichia coli; Proteus spp; Pseudomonas aeruginosa; Klebsiella spp; Staphylococcus aureus; Micrococus spp; Bacillus spp; e fungos como: Candida spp; Aspergillus niger; Penicillium spp; Fusarium spp; Rhizopus spp., sendo que a E. coli e Staphylococcus aureus apresentaram maior expressão numérica.

Martins et al. (2015) realizaram isolamento e identificação dos micro-organismos presentes em RSS do município de Santa Fé do Sul (SP) e constataram elevadas concentrações de micro-organismos patogênicos, principalmente na área hospitalar, uma vez que, neste ambiente, ocorre um percentual elevado de procedimentos invasivos e clientes susceptíveis a infecções hospitalares. As espécies isoladas foram Escherichia coli, Pseudomonas aeruginosa, Candida albicans, Clostridium tetani, Staphylococcus sp, Aspergillus niger, Trichophyton mentagrophytes, Microsporum gypseum e Clostridium sp.

Em função da carga microbiana elevada os RSS requerem tratamento especial durante todo o processo de segregação. Os cuidados com os resíduos infectantes iniciamse no descarte, pela separação do material não contaminado, pois os resíduos sólidos que podem causar infecção devem ser submetidos a processos de tratamento em equipamento que promova redução de carga microbiana, para posteriormente serem encaminhados para aterro sanitário licenciado ou local devidamente licenciado para disposição final (BRASIL, 2005).

Nos processos de tratamento dos RSS objetiva-se a destruição ou inativação irreversível de todos os agentes patogênicos presentes e a prevenção da recuperação ou reinfecção com estes agentes. (ZHANG et al., 2007; ALAGÖZ, KOCASOY, 2008; OLIVEIRA et al., 2010). Estes procedimentos devem anteceder à deposição final para presevar a saúde pública e ambiental. Estudos realizados por Bassey et al. (2015), utilizando procedimentos microbiológicos padrão de detritos sólidos em decomposição, do lixiviado, do solo e do ar evidenciaram que as bactérias predominantes foram Escherichia coli, Chromobacterium spp, Staphylococcus spp., Salmonella spp Klebsiella spp. As altas contagens bacterianas associadas a estes achados são indicativas do risco elevado de infecções microbianas.

Outra questão a ser considerada em relação aos aterros sanitários e a necessidade de tratamento eficiente dos RSS são os bioaerossóis gerados, que se constituem em fontes de poluição microbiana do ar. Os micro-organismos são transportados do aterro sanitário para a atmosfera com o vento onde permanecem suspensos. A emissão de bioaerossóis é considerável e pode atingir 1000-1200 m do local de emissão (TRAVERSI et al. 2011). Em amostras de ar coletadas do aterro e nas proximidades foram isoladas bactérias pertencentes aos gêneros Escherichia, Proteus, Enterobacter e Klebsiella. Entre as leveduras o gênero Candida foi identificado. Sua presença no ar pode representar uma ameaça potencial para a saúde humana, reforçando a necessidade de tecnologias eficientes capazes de eliminar a carga microbiana dos RSS (KAŹMIERCZUK, 
BOJANOWICZ-BABLOK, 2014).

A fumigação de materiais com gás ozônio pode constituir um sistema antimicrobiano alternativo eficaz, uma vez que é capaz de penetrar em todas as irregularidades superficiais e é aplicável a um amplo espectro microbiano (SHARMA, HUDSON, 2008; ROSENBLUM et al., 2012; MARTINS et al., 2015; MARTINELLI et al., 2017). Devido à sua meia vida curta, sua toxicidade e reatividade o ozônio deve ser produzido no local, em que reage principalmente com ligações duplas carbono-carbono, estruturas aromáticas ativadas e aminas não protonadas. O ozônio reage mais lentamente com ácidos graxos e carboidratos, e mais rapidamente com proteínas, aminas, aminoácidos, ácidos nucleicos e grupos funcionais de proteínas (ROSENBLUM et al., 2012).

Tabela 1. Média \pm desvio padrão da contagem microbiana de amostras de RSS das: Unidade de Terapia Intensiva Adulto (UTI Adulto), Unidade de Internação e Unidade de Isolamento de um hospital particular do Município de Uberlândia, MG, Brasil

\begin{tabular}{|c|c|c|c|c|}
\hline \multirow[b]{2}{*}{ Micro-organismo } & \multicolumn{3}{|l|}{ Local de coleta } & \multirow[b]{2}{*}{ Valor $\mathrm{p}^{1}$} \\
\hline & UTI adulto & $\begin{array}{l}\text { Unidade de } \\
\text { internação }\end{array}$ & $\begin{array}{l}\text { Unidade de } \\
\text { isolamento }\end{array}$ & \\
\hline Mesófilos totais & $2,7.10^{4} \pm 1,2.10^{4} \mathrm{c}$ & $1,6.10^{5} \pm 3,2.10^{4} b$ & $3,2.10^{6} \pm 1,1.10^{6} a$ & $<0,001$ \\
\hline Coliformes totais & $9,8 \cdot 10^{1} \pm 5,3 \cdot 10^{1} \mathrm{c}$ & $5,6 \cdot 10^{2} \pm 1,2 \cdot 10^{2} b$ & $3,9.10^{3} \pm 5,4.10^{3} a$ & $<0,001$ \\
\hline $\begin{array}{l}\text { Coliformes } \\
\text { termotolerantes }\end{array}$ & $2,7.10^{1} \pm 5,9.10^{0} \mathrm{~b}$ & $4,3.10^{1} \pm 1,7.10^{0} \mathrm{a}$ & $3,0.10^{2} \pm 2,4.10^{2} a$ & $<0,001$ \\
\hline Escherichia coli & $5,7.10^{0} \pm 1,0.10^{\circ} \mathrm{b}$ & $2,2 \cdot 10^{1} \pm 8,6 \cdot 10^{0} \mathrm{a}$ & $4,5 \cdot 10^{1} \pm 2,1.10^{1} \mathrm{a}$ & $<0,001$ \\
\hline $\begin{array}{l}\text { Pseudomonas } \\
\text { aeruginosa }\end{array}$ & $6,7.10^{0} \pm 2,5.10^{0} \mathrm{a}$ & $9,2.10^{0} \pm 3,7.10^{0} \mathrm{a}$ & $3,8.10^{\circ} \pm 1,6.10^{\circ} \mathrm{b}$ & 0,005 \\
\hline Proteus spp. & $0,0 \pm 0,0$ & $2,5 \cdot 10^{\circ} \pm 0,9 \cdot 10^{0}$ & $7,8.10^{\circ} \pm 1,5.10^{\circ}$ & - \\
\hline Staphylococcus aureus & $1,8.10^{1} \pm 1,3.10^{0} \mathrm{~b}$ & $1,6.10^{1} \pm 2,0.10^{0} \mathrm{~b}$ & $4,3 \cdot 10^{1} \pm 2,2 \cdot 10^{1} \mathrm{a}$ & 0,007 \\
\hline Staphylococcus spp. & $1,6.10^{0} \pm 0,5.10^{\circ} \mathrm{b}$ & $5,7 \cdot 10^{0} \pm 0,4 \cdot 10^{0} \mathrm{a}$ & $5,7.10^{0} \pm 1,9.10^{0} a$ & $<0,001$ \\
\hline Candida albicans & $4,4 \cdot 10^{1} \pm 3,8 \cdot 10^{1}$ & $1,7.10^{1} \pm 1,0.10^{1}$ & $2,9.10^{1} \pm 1,6.10^{1}$ & 0,101 \\
\hline Rhizopus spp. & $1,8.10^{0} \pm 0,3.10^{\circ} \mathrm{b}$ & $4,8.10^{0} \pm 1,1.10^{0} \mathrm{a}$ & $2,3 \cdot 10^{0} \pm 0,7 \cdot 10^{\circ} \mathrm{b}$ & $<0,001$ \\
\hline
\end{tabular}

1 Valor $\mathrm{p}$ referente ao teste de Análise de Variância a $\mathrm{P}<0,05$. Letras diferentes na mesma linha indicam diferenças significativas pelo teste de comparação múltipla de Games-Howell a $\mathrm{P}<0,05$.

A propriedade bactericida do ozônio foi demonstrada em micro-organismos Grampositivos (Listeria monocytogenes, Staphylococcus aureus, Enterococcus faecalis) e Gramnegativos (Yersinia enterocolitica, $P$. aeruqinosa, Salmonella typhimurium) e em esporos (GUÍZEL-SEYDIM et al., 2004). Foram identificados dois mecanismos principais pelos quais o ozônio exerce o efeito bactericida. Um deles é a oxidação de grupos sulfidrilo e aminoácidos de enzimas, peptídeos e proteínas. O outro mecanismo é baseado na oxidação dos ácidos graxos poli-insaturados (PUFAs). Nas bactérias Gram-negativas os efeitos destrutivos incidem nas camadas de lipoproteína e lipopolissacarídeos, o que contribui para o aumento da permeabilidade das células, que resulta na sua lise. O ozônio atua como um oxidante intracelular (THANOMSUB et al., 2002; RUSSELL, 2003).

A Tabela 2 evidencia os resultados da ação antimicrobiana do ozônio em relação às amostras dos resíduos coletadas nos três locais de estudo. Os resultados sugerem a existência de diferenças significativas na contagem microbiana nas amostras dos resíduos sem tratamento e após a ozonização, mostrando que as amostras de RSS da unidade de isolamento foram as que apresentaram maiores contagens de micro-organismos, sendo as 
que apresentaram menor eficiência na desinfecção quando submetidas à ozonização pelos intervalos de tempos pré-determinados para as análises. O intervalo de tempo de 15 minutos foi o suficiente para que as amostras da UTI adulto e da unidade de internação apresentassem contagem nula de micro-organismos, resultado que evidenciou a eficácia da ação do ozônio nas amostras de resíduos coletadas nesses locais. Para as amostras da unidade de isolamento foi necessário um intervalo de tempo de 20 minutos para que o mesmo efeito ocorresse.

Tormin et al. (2016) avaliaram o poder bactericida do ozônio gasoso sobre as bactérias multirresistentes Staphylococcus aureus, Acinetobacter baumannii, Enterococcus faecalis resistentes à vancomicina e Pseudomonas aeruginosa. Observaram que após infusão por 4 minutos de ozônio gasoso na concentração de $10 \mu \mathrm{g} \mathrm{mL}^{-1}$ não houve crescimento bacteriano nas leituras de $48 \mathrm{~h}$ e após 7 dias. Já nas concentrações de $4 \mu \mathrm{g} \mathrm{mL}-1$ e $3 \mu \mathrm{g} \mathrm{mL}^{-1}$, constataram crescimento bacteriano, embora em menores quantidades, mostrando ação bactericida parcial. Os autores concluíram que o ozônio tem efeito bactericida sobre bactérias multirresistentes, sendo este efeito proporcional à concentração e ao tempo de exposição. Nogales et al. (2014) compararam a atividade antimicrobiana de 3 diferentes concentrações de ozônio em Pseudomonas aeruginosa, Staphylococcus aureus e Enterococcus faecalis e constataram que o ozônio aquoso em concentração de $8 \mu \mathrm{g} \mathrm{mL}^{-1}$ foi o mais eficiente para eliminar as três bactérias avaliadas.

No entanto, há possibilidade de variação na sensibilidade dos diferentes microorganismos quando expostos ao ozônio e fatores ambientais podem afetar a inativação dos mesmos. Em ensaio in vitro conduzido em ágar com patogéneos Gram-positivos e Gramnegativos não foi observada diferença significativa nas contagens de colônias quando foram empregados tratamentos com concentração de ozônio entre 10 ppm e 50 ppm. Isto é possivelmente em razão de as células serem fisicamente protegidas por outras na superfície do ágar, isto é, quando as células são espalhadas no meio de cultura, algumas podem não estar presentes como células individuais, mas como grupos que proporcionam protecção física (WANI et al., 2015).

Diante dos resultados da Tabela 3 é possível pressupor que o intervalo de tempo de 15 minutos de exposição dos resíduos ao ozônio foi eficaz para promover a desinfecção desses materiais. Além disso, é possível observar que nos primeiros cinco minutos de exposição desses materiais ao ozônio, a carga microbiana atingiu reduções superiores a 98\%. Martinelli et al. (2017) investigaram a eficácia do tratamento do ozônio (aquoso e gasoso) como uma tecnologia sanitizante alternativa aos desinfetantes convencionais comuns na redução da contaminação microbiana da água e do ar. Os tratamentos com ozônio aquoso e gasoso foram eficazes contra contaminantes microbianos, reduzindo as unidades formadoras de colônias dos micro-organismos $E$. coli (26,4\% de redução), $P$. aeruginosa $(57,4 \%)$, S. aureus $(98,9 \%)$, Streptococcus faecalis $(64,2 \%)$ e Legionella pneumophila $(87,5 \%)$, constituindo-se em uma alternativa extremamente promissora, permitindo a possibilidade de reutilização de água contaminada.

Tabela 2. Média \pm desvio padrão da contagem microbiana das amostras de RSS dos locais avaliados de 
acordo com à ação antimicrobiana do ozônio

\begin{tabular}{|c|c|c|c|c|c|}
\hline \multirow[b]{2}{*}{$\begin{array}{l}\text { Ação } \\
\text { antimicrobiana } \\
\text { do ozônio }\end{array}$} & \multirow[b]{2}{*}{$\begin{array}{l}\text { Concentrações } \\
\text { de ozônio }\end{array}$} & \multicolumn{3}{|l|}{ Local de coleta } & \multirow[b]{2}{*}{ Valor $\mathrm{p}^{1}$} \\
\hline & & UTI adulto & $\begin{array}{l}\text { Unidade de } \\
\text { internação }\end{array}$ & $\begin{array}{l}\text { Unidade de } \\
\text { isolamento }\end{array}$ & \\
\hline Sem ozônio & 0 & $2,8.10^{4} \pm 1,2.10^{4} c$ & $1,7.10^{5} \pm 2,1.10^{4} b$ & $3,3.10^{6} \pm 1,1.10^{6} a$ & $<0,001$ \\
\hline $\begin{array}{l}\text { Ozônio } 5 \\
\text { minutos }\end{array}$ & $140 \mathrm{mg} \mathrm{L}^{-1}$ & $8,0.10^{1} \pm 4,8.10^{1} b$ & $2,2.10^{3} \pm 9,8.10^{2} a$ & $5,6.10^{3} \pm 3,5 \cdot 10^{3} \mathrm{a}$ & $<0,001$ \\
\hline $\begin{array}{l}\text { Ozônio } 10 \\
\text { minutos }\end{array}$ & $280 \mathrm{mg} \mathrm{L}^{-1}$ & $7,0.10^{\circ} \pm 6,0.10^{\circ} \mathrm{c}$ & $1,9.10^{1} \pm 7,9.10^{0} \mathrm{~b}$ & $9,2 \cdot 10^{1} \pm 5,4 \cdot 10^{0} \mathrm{a}$ & $<0,001$ \\
\hline $\begin{array}{l}\text { Ozônio } 15 \\
\text { minutos }\end{array}$ & $420 \mathrm{mg} \mathrm{L}^{-1}$ & $0,0 \pm 0,0$ & $0,0 \pm 0,0$ & $0,8 \cdot 10^{0} \pm 0,3 \cdot 10^{0}$ & - \\
\hline $\begin{array}{l}\text { Ozônio } 20 \\
\text { minutos }\end{array}$ & $560 \mathrm{mg} \mathrm{L}^{-1}$ & $0,0 \pm 0,0$ & $0,0 \pm 0,0$ & $0,0 \pm 0,0$ & - \\
\hline $\begin{array}{l}\text { Ozônio } 25 \\
\text { minutos }\end{array}$ & $700 \mathrm{mg} \mathrm{L}^{-1}$ & $0,0 \pm 0,0$ & $0,0 \pm 0,0$ & $0,0 \pm 0,0$ & - \\
\hline
\end{tabular}

Tabela 3. Média \pm desvio padrão do percentual de redução da carga microbiana devido à ação do ozônio nas amostras de RSS dos locais avaliados no estudo

\begin{tabular}{llll}
\hline \multirow{2}{*}{ Redução (\%) } & Local & & \\
\cline { 2 - 4 } & UTI adulto & Unidade de internação & $\begin{array}{l}\text { Unidade de } \\
\text { isolamento }\end{array}$ \\
\hline Inicial -5 min & $99,5 \pm 0,3$ & $98,7 \pm 0,4$ & $99,7 \pm 0,1$ \\
Inicial -10 min & $99,9 \pm 0,0$ & $99,9 \pm 0,0$ & $99,9 \pm 0,0$ \\
Inicial - 15 min & $100 \pm 0,0$ & $100 \pm 0,0$ & $100 \pm 0,0$ \\
Inicial - 20 min & $100 \pm 0,0$ & $100 \pm 0,0$ & $100 \pm 0,0$ \\
Inicial - 25 min & $100 \pm 0,0$ & $100 \pm 0,0$ & $100 \pm 0,0$ \\
\hline
\end{tabular}

É evidente que existe um interesse crescente em identificar uma tecnologia confiável para o manuseio e descarte seguro de resíduos sólidos da saúde. As tecnologias disponíveis como a incineração e a autoclavagem amplamente utilizadas apresentam em alguns casos riscos a saúde pública e ambiental. A incineração de RSS acarreta a liberação de poluentes, entre eles a dioxina que está ligada a doenças como o câncer, diabetes, defeitos congênitos, do sistema imunológico, entre outras. Tem sido relatado que os incineradores de resíduos da saúde são uma das principais fontes de dioxinas e mercúrio no ambiente (HAMER, 2003; MATTIELLO et al., 2013; ASHWORTH et al., 2014; ÖKTEN et al., 2015). A incineração pode, portanto, ser considerada como uma tecnologia inadequada para o tratamento de RSS.

Nos últimos anos, ambientalistas e agências de políticas públicas têm procurado definir tecnologias de esterilização adequadas para os RSS, para assegurar a possibilidade de reciclagem e a reutilização de alguns materiais. Neste contexto, o tratamento com autoclave a vapor está recebendo considerável atenção como possível alternativa à incineração, bem como o desenvolvimento sustentável da gestão, pois favorece a logística reversa a partir de resíduos esterilizados (HAMER, 2003; OLIVEIRA et al., 2010; ÖKTEN et al., 2015).

Em vista a avaliar os custos de investimento e de funcionamento das diferentes tecnologias de tratamento de $10.000 \mathrm{~kg}$ resíduos de serviços de saúde, Ökten et al. (2015) realizaram um estudo comparando as tecnologias de autoclave, de conversão e de 
ozonização. Em todos os sistemas o investimento inicial do sistema tinha um custo fixo definido como o primeiro custo pago para a aquisição do sistema. Os custos operacionais foram as variáveis de energia elétrica, de consumo de água e de gás natural. O consumo de água da autoclave foi significativamente maior; na ozonização o consumo foi mínimo e as águas residuais não foram produzidas no final do tratamento. A capacidade de tratamento, em horas, seriam necessárias $20 \mathrm{~h}$ com o conversor, $12,5 \mathrm{~h}$ com o ozonizador e, $26 \mathrm{~h}$ com a autoclave. Os custos mensais foram menores com a ozonização, 925,6 dólares, enquanto que com o conversor e autoclave foram de 12.036 e 9.418,24 dólares, respectivamente. A técnica de descontaminação por ozonizaçao foi a opção economicamente mais vantajosa para o tratamento de resíduos de serviços da saúde.

\section{CONSIDERAÇÕES FINAIS}

As vantagens da ozonização apresentadas e a eficácia antimicrobiana comprovadas nesta pesquisa evidenciam a possibilidade da sua utilização no controle de bactérias patogênicas na área da saúde, na descontaminação de ambientes, de resíduos, de efluentes, de instrumentais, entre outros.

\section{REFERÊNCIAS}

ALAGÖZ, Aylin Zeren; KOCASOY, Günay. Determination of the best appropriate management methods for the health-care wastes in İstanbul. Waste Management, New York, v. 28, 1227-1235, fev. 2008.

APHA-American Public Health Association. Standard methods for the examination of water and wastewater (22nd ed.). Washington, DC: American Public Health Association, 2012.

ASHWORTH, Danielle C.; ELLIOTT, Paul; TOLEDANO, Mirielle B. Waste incineration and adverse birth and neonatal outcomes: A systematic review. Environmental International London, v. 69, p.120-132, nov. 2014.

BASSEY, Ini U. et al. Environmental and Public Health Aspects of Solid Waste Management at the Lemna Dumpsite in Calabar, Cross River State, Nigeria. International Journal of Tropical Disease \& Health, Chicago, v. 10, n.3, p.1-13, jan. 2015, doi: 10.9734/ijtdh/2015/20023

BLENKHARN, Ian. Safe disposal and effective destruction of clinical wastes. Journal of Hospital Infection, London, v. 60, p. 295-297, set. 2005.

BRASIL. Ministério do Meio Ambiente. Conselho Nacional do Meio Ambiente. Resolução n. 358, de 29 de abril de 2005. Dispõe sobre o tratamento e a disposição final dos resíduos dos serviços de saúde e dá outras providências. Brasília, 2005. Disponível em: http://www.mma.gov.br/port/conama/legislacao/CONAMA_RES_CONS_2005_358.pdf 
CHAYB, Edilza Felicia; KOZUSNY-ANDREANI, Dora Inés. Estudo comparativo da contaminação por micro-organismos patogênicos em resíduos domiciliares e de saúde em Uberlândia (MG). Revista Brasileira Ciências Ambientais, Rio de Janeiro, v. 37, set. 2015; doi: 10.5327/Z2176-9478201512414

COCCIA, Ana Maria et al. Airborne microorganisms associated with waste managemet al.ent and recovery: biomonitoring methodologies. Annali dell'Istituto Superiore Di Sanita, Roma, v.46, n.3, p.288-292, 2010. doi: 10.4415/ANN_10_03_11.

COKER, Akinwale et al. Medical waste management in Ibadan, Nigeria: Obstacles and prospects. Waste Management, New York, v.29, n.2, p.804-811, fev. 2009.

doi.org/10.1016/j.wasman.2008.06.040

GAUTAM, Vidhi; THAPAR, Rajni.; SHARMA Mohita, Resham. Biomedical waste management: Incineration vs. environmental safety. Indian Journal of Medical Microbiology, New Delhi, v.28, p.191-192, jul-set. 2010. http://www.ijmm.org/text.asp?2010/28/3/191/66465

GÜZEL-SEYDIM, Zeynep; BEVER, Paul; GREENE, Annel. Efficacy of ozone to reduce bacterial populations in the presence of food components. Food Microbiology, Estados Unidos, v.21, n.4, p.475-479, aug. 2004. doi.org/10.1016/j.fm.2003.10.001

HAMER, Geoffrey. Solid waste treatment and disposal: effects on public health and environmental safety. Biotechnology Advances, London, v.22, p.71-79, dec. 2003. doi.org/10.1016/j.biotechadv.2003.08.007

HOSSAIN, Sohrab et al. Treatment of Clinical Solid Waste Using a Steam Autoclave as a Possible Alternative Technology to Incineration. International Journal Environmental Research and Public Health, Switzerland, v.9, n.3, p. 855-867;mar. 2012, doi:10.3390/ijerph9030855

KAŹMIERCZUK, Marcin; BOJANOWICZ-BABLOK, Anna. Bioaerosol concentration in the air surrounding municipal solid waste landfill. Environmental Protection and Natural Resource, ,Polonia v.25, n. 2(60), p. 17-25, jun. 2014. doi: 10.2478/oszn-2014-0015

MATTIELLO, Amalia et al. Health effects associated with the disposal of solid waste in landfills and incinerators in populations living in surrounding areas: A systematic review. International Journal of Public Health, Switzerland, v.58, p.725-735, oct. 2013. doi.org/10.1007/s00038-013

MARTINELLI, Mauro et al. Water and air ozone treatment as an alternative sanitizing technology. Journal of Preventive Medicine and Hygiene, Roma, v.58 n.1, , E48-E52, mar. 2017. doi.org/10.15167/2421-4248/jpmh2017.58.1.757

MARTINS, Carmem Costa; KOZUSNY-ANDREANI, Dora Inés; MENDES, Elena Carla Batista. Ozônio no controle de micro-organismos em resíduos de serviços de saúde. Revista Baiana Enfermagem, Salvador, v.29, n.4, p.318-29, out/dez. 2015. doi.org/10.18471/rbe. v29i4.13678.

MURRAY, Byron K. et al. Virion disruption by ozone-mediated reactive oxygen species. Journal of Virological Methods, London, v.153, p.74-77, jul. 2008.

doi.org/10.1016/j.jviromet.2008.06.004 
NASCIMENTO, Thiago Cesar et al. Ocorrência de bactérias clinicamente relevantes nos resíduos de serviços de saúde em um aterro sanitário brasileiro e perfil de susceptibilidade a antimicrobianos. Revista da Sociedade Brasileira de Medicina Tropical, Uberaba, v.42, n.4, p.415-419, jul/ago. 2009. doi.org/10.1590/S003786822009000400011.

NOGALES, Carlos Goes et al. Comparison of the antimicrobial activity of three different concentrations of aqueous ozone on Pseudomonas aeruginosa, Staphylococcus aureus, and Enterococcus faecalis - in vitro study. Revista Espãnola Ozonoterapia, Madrid, v.4, n.1, p.9-15, 2014.

OLIVEIRA, Emerson A. et al. Microwave inactivation of Bacillus atrophaeus spores in healthcare waste. Waste Management, ,New York, v. 30, p.2327-2335, nov. 2010. doi:10.1016/j.wasman.2010.05.002

ÖKTEN, Hatice Eser; CORUM, Adnan; DEMIR, Hacer Handan. A comparative economic analysis for medical waste treatment options. Environment Protection

Engineering,Polonia, v.41, n.3, 2015. doi: 10.5277/epe150310

PARK, Hongrae et al. Detection and hazard assessment of pathogenic microorganisms in medical waste. Journal of environmental science and health, Philadelphia, v. 44, p. 995-1003, ago. 2009. http://www.tandfonline.com/loi/lesa

ROSENBLUM, James et al. Ozonation as a clean technology for fresh produce industry and environment: sanitizer efficiency and wastewater quality. Journal of Applied Microbiology, Oxford, v.113, n.4, p.837-845, mar. 2012. doi: 10.1111/j.13652672.2012.05393.x.

RUSSELL, A. Denver. Similarities and differences in the responses of microorganisms to biocides. Journal of Antimicrobial Chemotherapy, London, v.52, n.5, p.750-763, nov. 2003. doi.org/10.1093/jac/dkg422

SAINI, Savita et al.. The study of bacterial flora of different types in hospital waste:

Evaluation of waste treatment at aims hospital, New Delhi. Southeast Asian Journal of Tropical Medicine and Public Health, Bangkok, v. 35,n.4, 986-989, dec. 2004.

SHARMA, Manju; HUDSON, James B. Ozone gas is an effective and practical antibacterial agent. American Journal of Infection Control, New York, v.36, p.559-63, oct. 2008. doi.org/10.1016/j.ajic.2007.10.021

SINGH Pragya, Impact of Solid Waste on Human Health: A Case Study of Varanasi City. International Journal of Scientific \& Engineering Research, Estados Unidos, v. 4, n.11, p.1840-1842, nov. 2013. http://www.ijser.org

THANOMSUB, Benjamas et al. Effects of ozone treatment on cell growth and ultrastructural changes in bacteria. Journal of Applied Microbiology,Oxford, v.48, p.193199, jun. 2002.

TORMIN, Stephanie Corradini et al. Análise do efeito bactericida do ozônio sobre bactérias multirressistentes. Arquivos médicos dos Hospitais e da Faculdade de Ciências Médicas da Santa Casa de São Paulo.São Paulo, v.61, p.138-141, 2016. 
TORTORA Geralda Jerry, FUNKE Berdell R., CASE Cristiane L. Microbiologia. 10ª ed. Porto Alegre: Artmed Editora SA; 2012.

TRAVERSI, Deborah et al. Size-fractionated PM10 monitoring in relation to the contribution of endotoxins in different polluted areas. Atmospheric Environmental, Estados Unidos, v.45, p. 3515-3521, jul. 2011. doi.org/10.1016/j.atmosenv.2011.04.020

WANI, Shreya et al. Effect of Ozone Treatment on Inactivation of Escherichia coli and Listeria sp. on Spinach. Agriculture, Switzerland, v.5, p.155-169, jun. 2015. doi:10.3390/agriculture5020155

WINN JUNIOR, Washington. et al. Diagnóstico microbiológico - texto e atlas colorido. 6‥ ed. Rio de Janeiro: Guanabara Koogan; 2008.

ZAR, Jerrold H. Biostatistical Analysis. 5th edition. Essex: Prentice Hall, 2009.

ZHANG, Jian et al. Supercritical carbon dioxide and hydrogen peroxide cause mild changes in spore structures associated with high killing rate of Bacillus anthracis. Journal of Microbiology Methods, Amsterdam, v. 70, p. 442-451, jun. 2007.

doi: 10.1016/j.mimet.2007.05.019 